\title{
INTERVENCIÓN CON FAMILIAS EN PUERTO RICO: UNA ESTRATEGIA COMUNITARIA
}

Dra. Sheila Archilla de Ortiz, ACSW; BCD; SSW'

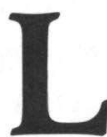

a profesión de Trabajo Social en Puerto Rico está en un proceso de reconceptualización de su misión y propósito a fin de mantener una mayor relevancia hacia los intereses, necesidades y problemas de la población puertorriqueña. De cara al milenio hemos venido desarrollando servicios para retomar las raíces que dieron lugar a la profesión: la comunidad. Además resulta vital centrar los servicios a las realidades de la vida moderna y al sistema familiar en su entorno comunitario en vez de al individuo en forma aislada. Es bien conocido que el modelo psicodinámico no ha traído índices de resultados positivos y efectivos en los participantes de estos servicios en una variedad de escenarios de práctica.

Este artículo recoge las experiencias de la autora en una práctica de trabajo social puertorriqueño centrada en las familias dentro de su entorno comunitario y desde una perspectiva saludable. Parte de la convicción de que la gente posee fortalezas y un poder personal para operar cambios ya sean en su medioambiente social así como también en su vida familiar. Existen transacciones humanas que son complementarias y que inducen al crecimiento personal, familiar y comunal. No obstante, debido a la falta de acceso y oportunidades que tienen las familias a los servicios del sistema de bienestar social y a que estos servicios no siempre responden a sus necesidades, los

${ }^{11}$ La doctora Archilla es Catedrática de la Escuela Graduada de Trabajo Social y Consultora del Proyecto S.I.P.A.F. (Servicios Integrales de Preservación y Apoyo Familiar). 
niveles de tensión negativa se acumulan, y como consecuencia éstos ocasionan disfunciones que impactan el funcionamiento familiar y la calidad de vida de las familias y de sus menores. El recurso más valioso que tiene un país es su gente. Entonces cabría preguntarnos, qué estamos haciendo para fomentar, apoyar, fortalecer y facilitar cambios en las familias en su entorno comunitario que permita su desarrollo integral y el de sus hijos.

El Proyecto de Servicios Integrales de Preservación y Apoyo Familiar, con el Multimétodo Empírico, mejor conocido por sus siglas como Proyecto S.I.P.A.F., es una estrategia interdisciplinaria innovadora y novedosa centrada en la familia dentro de la ecología comunitaria. Los servicios son auspiciados por la Administración de Familias y Niños del Departamento de la Familia en áreas geográficas de las Regiones de Bayamón, Carolina y San Juan. Su base legal la obtiene del Omnibus Reconciliation Act del 1991. Entre sus objetivos principales se identifican el ofrecer servicios intensivos y culturalmente sensitivos a las familias en el hogar, para la prevención y el tratamiento en situaciones de maltrato a menores; fomentar $\mathrm{y}$ fortalecer el desarrollo integral de las familias; fomentar el liderazgo comunal de adultos y adolescentes; dar acceso a las familias a los servicios de la comunidad y ofrecer servicios efectivos a los participantes, entre otros.

Trabajadores sociales y miembros del equipo interdisciplinario visitan a las familias en el hogar o en su hábitat natural, el cual es el lugar prioritario donde se dispensan los servicios. El trabajador social desempeña una variedad de roles profesionales donde se destacan los roles de practicante-investigador, facilitador de grupo, educador, promotor de cambio, analista-planificador, intercesor y mediador, entre otros roles profesionales.

El modelo de intervención profesional utilizado en el Proyecto S.I.P.A.F. es el Multimétodo Empírico (Archilla 1983, 1987, 1991, 1994, 1995 y 1996). Este modelo ha probado su utilidad para establecer índices de efectividad de los servicios en Trabajo Social ofrecidos a las familias. El trabajador social entra en el proceso de ayuda con la familia en su rol de practicante-investigador. Éste aprende de la familia cuál es su situación particular y juntos establecen objetivos, metas y los mecanismos de medición y monitoría del proceso de 
ayuda, el cual se agiliza desde su fase de ponderación o línea base hasta la fase de terminación y de mantenimiento, para mantener los resultados alcanzados y prevenir la reincidencia. La participación de la familia es vital en todas las fases ya que ésta evalúa progresivamente los adelantos o retrocesos en el proceso de ayuda. De ser necesario, se establecen acciones correctivas al plan de servicios con el propósito de ayudar a las familias y a su membresía a alcanzar los objetivos y las metas que éstas se han trazado.

La capacitación del personal en el modelo de intervención, la consultoría y la supervisión resultan tecnologías relevantes para garantizar la calidad de los servicios. Las familias en el Proyecto SIPAF tienen acceso directo al trabajador social mediante un comunicador electrónico. Éste reduce la distancia entre ambas partes y garantiza poder atender situaciones imprevistas o de emergencia.

La mediación de conflictos familiares es otra estrategia de intervención utilizada en el componente de servicios intensivos en el hogar. SIPAF utiliza el Modelo de Mediación Familiar y Resolución de Conflicto (Archilla, 1997). Este servicio ofrece a la familia la oportunidad de dirimir sus diferencias y desavenencias ante un tercero y bajo un clima propiciatorio al dialogo y de respeto a la toma de decisiones.

Además de este componente de servicios, el Proyecto SIPAF cuenta con otra estrategia comunitaria de servicios a las familias en su entorno comunal. En las comunidades donde opera SIPAF, se organizan grupos de padres a los que se les ofrecen Talleres de MaternidadPaternidad Efectiva para el Apoyo Familiar donde participan padres o encargados de menores. Se establece un comité comunitario el cual tiene representantes de todos los sectores comunitarios. La función principal de este grupo es establecer prioridades en cuanto a áreas a discutir en los talleres, desarrollar estrategias comunitarias de acercamiento y acción con los padres y evaluar los resultados obtenidos. Estos talleres han sido muy efectivos e instrumentales en la educación popular comunitaria para la prevención del maltrato a menores y para el fortalecimiento y apoyo familiar. Se han creado sistemas de apoyo comunitario de incalculable valor para la convivencia familiar y comunitaria y para el desarrollo de las familias.

SIPAF organiza grupos de adolescentes en la comunidad como 
parte de su estrategia preventiva. En cada área geográfica se preparan, conjuntamente con los adolescentes, talleres para el Desarrollo de Destrezas Interaccionales y de Responsabilidad Ciudadana. En estos talleres se utilizan técnicas interactivas y técnicas no tradicionales tales como: la pantomima, el teatro del pueblo, la música rap y reggae, entre otras. Los adolescentes han desarrollado liderazgo efectivo en sus comunidades, y su participación en los grupos de adolescentes ha sido evaluada en forma positiva tanto por sus familias como por sus maestros.

Para los niños se organiza la Semana Recreativa, Certámenes de Dibujo, Día de Juegos, todos dirigidos al crecimiento personal, a fomentar valores de convivencia familiar y a promover la superación como persona. Los niños también participan en los procesos familiares y se les ofrece seguimiento a sus necesidades particulares.

En la fase de mantenimiento, las actividades especiales constituyen una estrategia novedosa. Las familias tienen la oportunidad de compartir con otras familias y con el equipo SIPAF. Estas actividades son variadas: Encuentros Familiares, Día de Logros, Día Familiar SIPAF, entre otras actividades especiales. Esta estrategia es muy novedosa, ya que los miembros del equipo SIPAF interactúan con las familias y sus menores y se constatan los cambios logrados por la familia en su dinámica familiar y en su intercambio con otras familias.

La coordinación interagencial resulta muy significativa en la prestación de servicios a las familias. Esto es así por la diversidad de necesidades que tienen las familias en el mundo moderno. Los logros obtenidos en esta área han sido muy notables en maximizar las opciones para atender a las familias y optimizar la calidad de sus vidas y la de los menores.

Otros factores de gran relevancia en los logros obtenidos en el Proyecto SIPAF han sido su estructura organizacional, la visión gerencial y humanista de los procesos sociales en la organización y la participación de los consumidores o de la base de los servicios, es decir, de las familias, en la toma de decisiones. Éstos han resultado ser elementos vitales en la programación, implantación y evaluación de los servicios del Proyecto SIPAF y en su éxito en la prevención y el tratamiento del maltrato a menores en la comunidad puertorriqueña. 
Merece destacarse su filosofía de servicios, donde el poder del cambio está centrado en las familias y en la convicción de que toda familia posee fortalezas para lidiar con las tensiones del diario vivir. En este contexto, el trabajador social, en su rol de practicante-investigador, es quien, con la familia, identifica programa y promueve cambios para aumentar los conocimientos y las destrezas de manejo necesarias para que éstas puedan lidiar consigo mismas y con su medioambiente social dentro de la ecología comunitaria.

Los trabajadores sociales puertorriqueños estamos abriendo surcos hacia una práctica profesional no tradicional y de gran compromiso comunitario. La labor es ardua pero fructífera. Así ha quedado demostrado en las evaluaciones internas de proceso, en las evaluaciones externas sumativas y en la evaluación continua que las familias hacen de los diversos servicios. El pensamiento crítico y la autoreflexión de nuestro quehacer profesional nos motiva y mueve hacia una mayor excelencia cada día.

Por ser el problema del maltrato a menores uno multicausal, y los servicios de prevención y tratamiento unos procesos complejos, necesitamos continuar solidificando la base conceptual e integrando la misma a la práctica del Trabajo Social en Puerto Rico. El Proyecto SIPAF es evidencia de esta transformación en el contexto de la realidad social puertorriqueña.

iContinuaremos hacia la acción afirmativa, innovadora y renovadora en nuestras comunidades. Las familias así lo reclaman y la profesión de Trabajo Social está respondiendo a este reto de cara al milenio!

\section{Referencias}

Adams, P. et al. (1995). Reinventing Human Services: Community and Family Centered Practice. New York: Aldine.

Albee, G.W. (1994). Improving Children's Lives. London: Sage.

Combrinik, G.L. (1995). Children in Families at Risk: Maintaining the Connections. New York: Guilford Press.

Fraser, M. et al. Families in Crisis: The Impact of Intensive Family Preservation Services. New York: Aldine. 
Gitterman, A. et al. (1994). Mutual Aid Groups, Vulnerable Populations, and the Life Cycle. Second Edition. New York: Columbia.

Kruk, E. (1997). Mediation and Conflict Resolution. Chicago: Nelson-Hall.

Melton, G. et al. (1994). Protecting Children from Abuse and Neglect. New York: Sage.

Seaberg, J.R. (1990). Child well-being: A feasible concept? Social Work 35(3), 267 272.

Schuerman, J.R. et al. (1994). Putting Families First: An Experiment in Family Preservation. New York;: Aldine.

Wachtel, E. (1994). Treating Troubled Children and Their Families. New York: Guilford.

Wells, K. et al. (1992). Intensive family preservation services research: Current status and future agenda. Social Work Research 28(1) 21-27.

Whittaker, J.K. et al. (1990). Reaching High-Risk Families. New York: Aldine. 